\title{
Large duodenal GIST with massive liver secondaries melting under Imatinib: a case report S Sankar*1, M Subramanian² ${ }^{2}$ T Arunkumar ${ }^{3}$, N Venu ${ }^{4}$ and K Anand ${ }^{4}$
}

\begin{abstract}
Address: ${ }^{1}$ Department of Surgical gastroenterology, D-2 Private clinic, Sri Ramachandra Medical College \& Research Center, Chennai, 600116, Tamilnadu, India, ${ }^{2}$ Department of Surgical gastroenterology, D-2 Private clinic, Sri Ramachandra Medical College \& Research Center, Chennai, 600116, Tamilnadu, India, ${ }^{3}$ Department of Surgical gastroenterology, D-2 Private clinic, Sri Ramachandra Medical College \& Research Center, Chennai, 600116, Tamilnadu, India and ${ }^{4}$ Department of Surgical gastroenterology, D-2 Private clinic, Sri Ramachandra Medical College \& Research Center, Chennai, 600116, Tamilnadu, India
\end{abstract}

Email: S Sankar* - drsshankar@gmail.com; M Subramanian - gastrosurg@yahoo.co.in; T Arunkumar - arunsurgery70@yahoo.com; N Venu - venu369@yahoo.com; K Anand -dranand@hotmail.com

* Corresponding author

Published: 30 September 2008

Cases Journal 2008, I:197 doi:10.1186/1757-1626-1-197
Received: 2 July 2008

Accepted: 30 September 2008

\section{(C) 2008 Sankar et al; licensee BioMed Central Ltd.}

This is an Open Access article distributed under the terms of the Creative Commons Attribution License (http://creativecommons.org/licenses/by/2.0), which permits unrestricted use, distribution, and reproduction in any medium, provided the original work is properly cited.

\begin{abstract}
Gastrointestinal stromal tumors(GIST) have become a well established entity and its taxonomy is no more ambiguous. Better understanding of the cell of origin and immunohistochmical markers have made this possible. Their treatment has been revolutionized with the advent of targeted molecular therapy, namely Imatinib mesylate. Herein we report a rare and interesting case of a thirty year old South Indian Lady with an extremely large Duodenal GIST with massive Liver secondaries. The phenomenon of metastatic GIST responding to Imatinib mesylate is not new. What is interesting in this case is the enormous tumor load at the time of presentation as exemplified by the cross sectional images. This kind of tumor response and patient survival deserves documentation
\end{abstract}

\section{Case presentation}

Thirty year old South Indian Lady, a home maker presented to us in May 2005 with severe anemia and weight loss of three months duration. Her weight was $50 \mathrm{~kg}$ and height was $160 \mathrm{~cm}$. She was neither an alcoholic nor a smoker. She had few episodes of malena during this period. She also had abdominal fullness, but no vomiting or pain. Clinical examination revealed a very pale patient with gross hepatomegaly with nodularity suggestive of secondaries Liver. Except for a grossly low hemoglobin, her other hemogram and biochemistry were within normal levels. Esophagogastroduodenoscopy picked up a fleshy protruding tumor in the second part of the duodenum(fig 1 ). CT abdomen showed a highly vascular and bulky tumor arising from the second part of the duode- num with massive secondary deposits in both the lobes of Liver(fig 2\&3). Biopsies were done from the duodenal tumor and Liver metastasis. Histopathological report proved it to be Gastrointestinal stromal tumor(GIST) positive for CD 117.

Anemia was corrected with blood transfusion. Since she had a metastatic GIST, she was started on Imatinib mesylate $400 \mathrm{mg}$ once daily. The follow up CT showed a very dramatic response with almost complete clearance of metastatic deposit in the liver(fig 4). The duodenal tumor regressed in size(Fig 5). Since the Liver metastasis responded dramatically, we offered surgery for the primary duodenal tumor, which patient refused. At the point of writing this article, that is three years and six months 


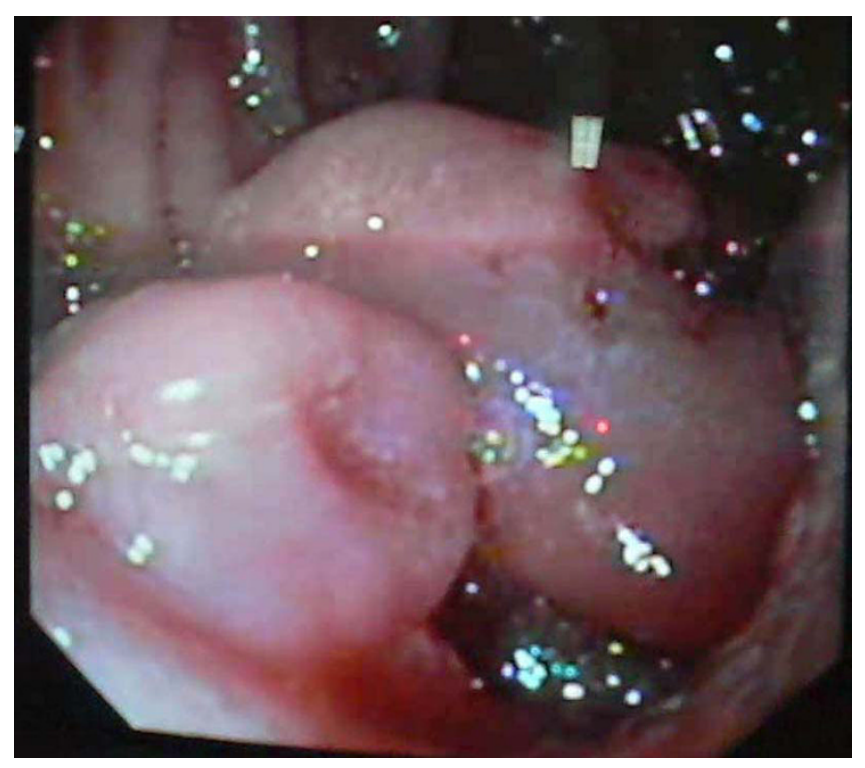

Figure I

Endophytic fleshy tumor of duodenum.

after diagnosis, patient is fine and asymptomatic and continues to take Imatinib mesylate.

\section{Discussion}

Gastrointestinal stromal tumor is not an uncommon entity in clinical practice with majority of them arising from stomach. Small intestine accounts for $20 \%-30 \%$ of

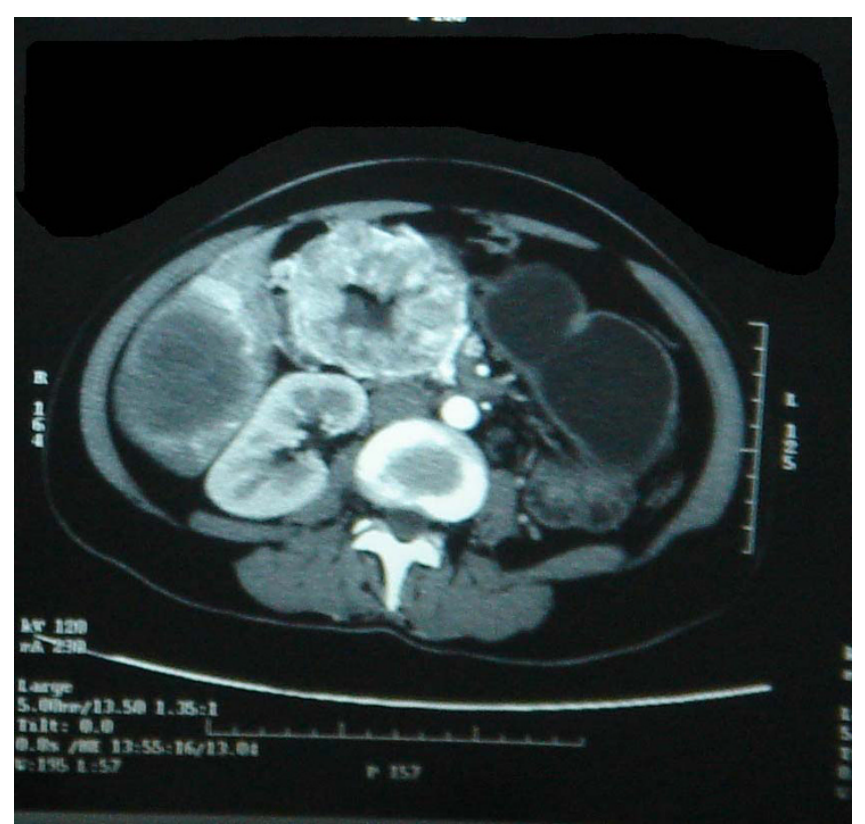

\section{Figure 2}

Large duodenal tumor with brisk contrast enhancement.



Figure 3

Massive bilobar liver metastasis.

the GIST. Majority of the small intestinal GIST arises from the jejunum and Ileum. Duodenum being the least common site. Duodenal GIST usually present with vague

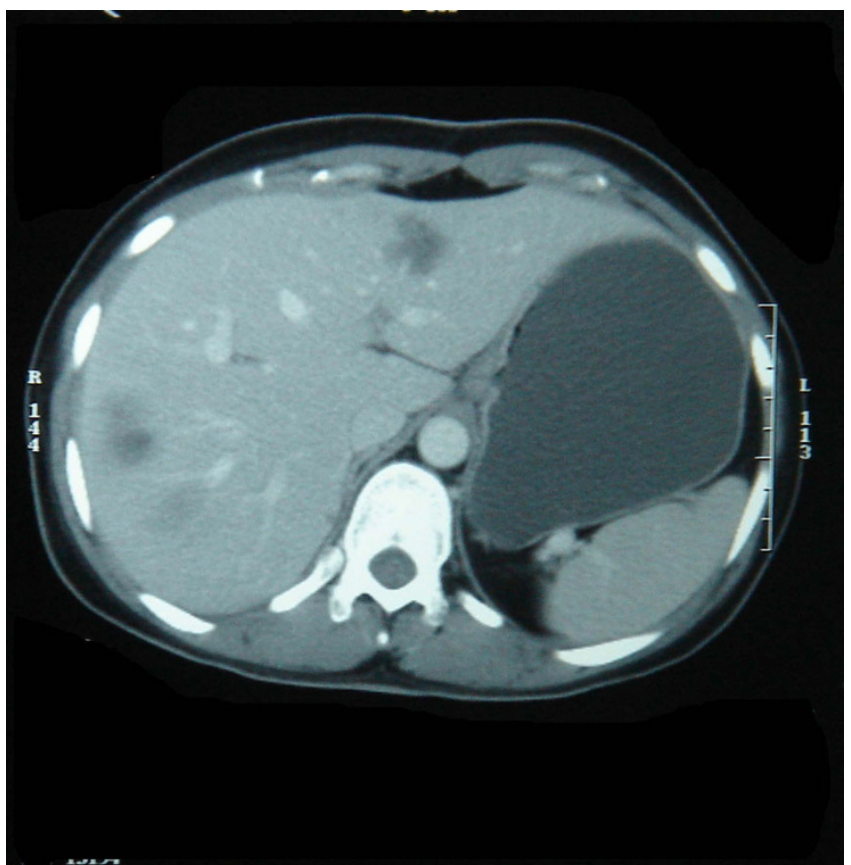

Figure 4

Dramatic response after Imatinib mesylate. 




Figure 5

Partial response of duodenal tumor.

abdominal pain $(50 \%-70 \%)$ or they bleed into the lumen(20\%-50\%)[1,2]. Small bowel GIST have a high propensity to exhibit malignant behavior[3]. Second part of the duodenum seems to be the common site of duodenal GIST and most of them will require pancreatoduodenectomy for complete resection[4]. Completely resected GIST has a five year survival of $30 \%-80 \%[5]$. Incompletely resected tumors have a high recurrence rate(upto 90\%). Historically Unresectable/metastatic GIST has a median survival of 12 months[6]. Imatinib mesylate, a specific tyrosikine kinase inhibitor has produced a paradigm shift in the treatment of GIST, due to the targeted molecular therapy. Imatinib produce sustained clinical response in more than $50 \%$ of the patients with advanced GIST and one year survival in these patients was $88 \%[7]$.

\section{Conclusion}

Metastatic GIST responding to Imatinib is not an unusual phenomenon. But considering the sheer size and magnitude of the primary and secondary deposit, the response to imatinib has been immaculate. With the kind of tumor load this patient had, survival for more than three years is worth documenting. This case of GIST is rare and unusual for the following reasons

\section{Duodenum being an uncommon site of GIST}

2. Age of the patient 30 years. Usual age of GIST is beyond 40 years
3. Phenomenal cell kill achieved with imatinib

4. Despite the various poor prognostic factors patient continues to survive without any symptoms

\section{Competing interests}

The authors declare that they have no competing interests.

\section{Authors' contributions}

SS prepared the manuscript, KA edited the photos and all others read and approved the manuscript.

\section{Consent}

Written and informed consent has been obtained from the patient for publication of the article and photos and the copy of the same is available for review by the editors.

\section{References}

I. Sturgeon C, Chejfec G, Espat NJ: Gastrointestinal stromal tumors: a spectrum of disease. Surg Oncol 2003, 1 2:2 I-26.

2. DeMatteo RP, Lewis JJ, Leung D, Mudan SS, Woodruff JM, Brennan MF: Two hundred gastrointestinal stromal tumors: recurrence patterns and prognostic factors for survival. Ann Surg 2000, 23 I:5 I-58.

3. DeMatteo RP, Heinrich MC, El-Rifai WM, Demetri G: Clinical management of gastrointestinal stromal tumors: Before and after STI-57I. Human Pathol 2002, 33:466-67.

4. Winfield, Robert D, Hochwald, Steven N, Vogel, Stephen B, Hemming, Alan W, Liu, Chen, Cance, William G, Grobmyer, Stephen R: American Surgeon 2006, 72:719-23.

5. Casper ES: Gastrointestinal stromal tumors. Curr Treat Options Oncol 2000, I:267-273.

6. Roberts PJ, Eisenberg B: Clinical presentation of gastrointestinal stromal tumors and treatment of operable disease. Eur J Cancer 2002, 38:S37-38.

7. Demetri GD, von Mehren M, Blanke CD, Abbeele AD Van den, Eisenberg B, Roberts PJ, Heinrich MC, Tuveson DA, Singer S, Janicek M, Fletcher JA, Silverman SG, Silberman SL, Capdeville R, Kiese B, Peng B, Dimitrijevic S, Druker BJ, Corless C, Fletcher CD, Joensuu H: Efficacy and safety of imatinib mesylate in advanced gastrointestinal stromal tumors. N Engl J Med 2002, 347:472-80.

Publish with Bio Med Central and every scientist can read your work free of charge

"BioMed Central will be the most significant development for disseminating the results of biomedical research in our lifetime. " Sir Paul Nurse, Cancer Research UK

Your research papers will be:

- available free of charge to the entire biomedical community

- peer reviewed and published immediately upon acceptance

- cited in PubMed and archived on PubMed Central

- yours - you keep the copyright
BiolMedcentral 